\title{
Pengaruh Mode Shape Frekuensi Alami terhadap Estimasi Gaya Tarik Batang Baja dengan Metode Vibrasi
}

\author{
(Effect of Shape Mode of Natural Frequency on Estimation of Tension Force of Steel Rods using \\ Vibration Method)
}

\section{GUNTUR NUGROHO}

\begin{abstract}
The vibration method has been widely applied to estimate the force on cable structures as well as beams. This method utilizes the natural frequency of structural elements in estimating tensile as well as compressive forces. On the cable element, a different natural frequency will appear according to the shape number. This study raises the suitability of force estimation by using the natural frequency of the first second and third modes. The steel specimen have cross section of width, thickness and length of $6 \mathrm{~mm}, 40 \mathrm{~mm}$ and $2000 \mathrm{~mm}$ respectively. The results of natural frequency, calculated by using analytic formulas (string, beam-string and stokey) has been compared with the natural frequency resulted by numerical modeling. The difference of natural frequency of specimen calculated by using analytic formulas (strings, beam-strings, stokey), compared with the result of numerical modeling has the smallest value in the first mode which is $3.75 \%$ at $5,000 \mathrm{~N}$ load and $0.61 \%$ at $50,000 \mathrm{~N}$ load.
\end{abstract}

Keywords: natural frequency, mode shape, vibration method

\section{METOde PENELITIAN}

\section{PENDAHUluan}

Estimasi tegangan dan gaya pada elemen struktur dengan menngunakan metode vibrasi telah banyak dilakukan. Aplikasi metode vibarasi bisa digunakan untuk elemen struktur yang menerima beban aksial tarik maupun beban aksial tekan. Mertode ini memanfaatkan nilai frekuensi alami yang ada pada elemen struktur untuk estimasi gaya dan tegangan.

Dalam satu elemen struktur akan ada beberapa nilai frekuensi yang frekuensi yang berbeda, hal tersebut dikarenakan adanya perbedaan nilai frekuensi pada setiap modenya. Semakin besar mode number maka nilai frekuensi alami akan semakin besar. Pemilihan data frekuensi alami yang digunakan untuk estimasi gaya dan tegangan disesuaikan dengan rumus analitik metode vibrasi pada setiap mode number.

Penelitian ini bertujuan untuk mengetahui kesesuaian antara frekuensi alami hasil perhitungan analitik dengan hasil pemodelan numerik pada ketiga mode yang pertama dengan metode perhitungan analitik dan pemodelan numerik menggunakan software Abaqus.

\section{String theory}

Pada metode string theory mengabaikan kedua parameter lendutan dan kekakuan lentur kabel (Saxon dan Chan 1953; Irvine 1981):

$$
T=4 m L^{2}\left(\frac{f_{n}}{n}\right)^{2}
$$

dengan:

$$
\begin{aligned}
\mathrm{T} & =\text { gaya aksial }(\mathrm{N}) \\
\mathrm{m} & =\operatorname{massa}(\mathrm{kg} / \mathrm{m}) \\
\mathrm{L} & =\text { panjang }(\mathrm{m}) \\
\mathrm{f}_{\mathrm{n}} & =\text { frekuensi alami }(\mathrm{Hz}) \\
\mathrm{n} & =\text { mode number }
\end{aligned}
$$

Gaya tarik dapat dengan mudah ditetapkan dari pengukuran beberapa variable tersebut. Akan tetapi formula pada Persamaan 1 hanya valid untuk tipe kabel yang langsing, datar dan tunggal. Meskipun Persamaan 1 tidak valid untuk kabel dengan lendutan yang besar, kekakuan lentur dan sistem dengan dobel hanger, metode ini sangat bermanfaat untuk pendekatan gaya tarik pertama. 


\section{Beam-string theory}

Shimada dkk, (1994) dan Humar (1990) memperkenalkan formula yang biasa digunakan pada balok yang dibebani aksial tarik dengan memasukkan parameter kekakuan lentur tanpa memperhitungkan lendutan.

$\left(\frac{f_{n}}{n}\right)^{2}=\left(\frac{1}{4 m l^{2}}\right) T+\left(\frac{n^{2} \pi^{2}}{4 m L^{4}}\right) E I$

dengan:

$\mathrm{T} \quad=\quad$ gaya aksial $(\mathrm{N})$

$\mathrm{m}=\operatorname{massa}(\mathrm{kg} / \mathrm{m})$

$\mathrm{L} \quad=\quad$ panjang $(\mathrm{m})$

$\mathrm{f}_{\mathrm{n}} \quad=$ frekuensi alami $(\mathrm{Hz})$

$\mathrm{n}=$ mode number

EI $=$ kekakuan lentur $\left(\mathrm{Nm}^{2}\right)$

Dengan menghubungkan gaya tarik yang belum diketahui dan kekakuan lentur, prosedur regresi linier diaplikasikan untuk mengukur frekuensi dan hubungan nomer modenya. Kekakuan lentur (EI) dan tegangan kabel dapat secara bersamaan diestimasi. Meskipun estimasi yang dihasilkan sangat akurat untuk kabel dengan tipe single, pendek dan besar, estimasi pada kekakuan lentur tidak akurat untuk kabel dengan lendutan besar. Walaupun ada beberapa batasan, pendekatan ini sering digunakan karena bisa digunakan dengan cepat dan simpel.

\section{Stokey theory}

Stokey (1998) memperkenalkan formulasi praktis untuk menghitung frekuensi alami batang yang diberikan beban aksial sebagai berikut:

$$
f_{n}=\frac{\kappa^{2}}{2 \pi L^{2}} \sqrt{\frac{E I}{m}} \sqrt{1 \pm \frac{F L^{2}}{E I \pi^{2} n^{2}}}
$$

Dimana nilai $\mathrm{f}_{\mathrm{n}}$, $\mathrm{L}$, EI dan $\mathrm{n}$ adalah frekuensi alam $(\mathrm{Hz})$, panjang batang $(\mathrm{m})$, kekakuan lentur $\left(\mathrm{kNm}^{2}\right)$ dan mode number. Sedangkan nilai $\mathrm{K}$ adalah parameter yang didasrkan pada jenis tumpuan yang digunakan, adapun nilai $\mathrm{K}$ dapat dilihat pada Tabel 1 .

\section{Pemodelan Numerik}

Pemodelan numerik yang dilakukan pada penelitian ini adalah dengan menggunakan batang strip baja yang mempunyai ukuran (6x40x2000) mm. Tahapan pemodelan numerik dengan menggunakan softwae abaqus meliputi beberapa tahap sebagai berikut:

\section{Part}

Pada bagian part elemen batang digambar menggunakan elemen strip plat solid 3 dimensi dengan ukuran panjang $2000 \mathrm{~mm}$ dan penampang melintang persegi dengan ukuran tanpang $6 \mathrm{~mm} \times 40 \mathrm{~mm}$. Detail visualisasi gambar dapat dilihat pada Gambar 1 .

TABEL 1. Nilai K pada berbagai kondisi batas ujung tumpuan

\begin{tabular}{cccc}
\hline Ujung & \multicolumn{3}{c}{ Nilai K } \\
\cline { 2 - 4 } Tumpuan & Mode 1 & Mode 2 & Mode 3 \\
\hline Sendi-sendi & 3,146 & 6,283 & 9,425 \\
Jepit-jepit & 4,730 & 7,853 & 10,996 \\
Jepit-sendi & 3,927 & 7,069 & 10,210 \\
Jepit-bebas & 1,875 & 4,694 & 7,855 \\
\hline
\end{tabular}

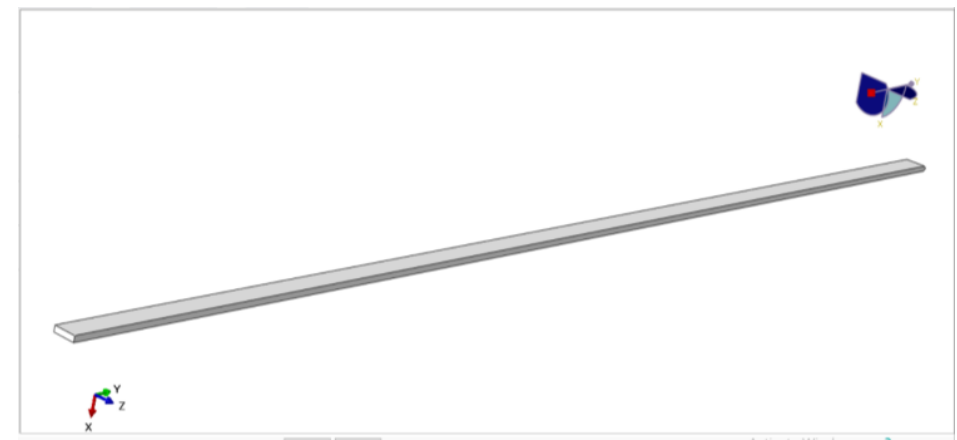

Gambar 1. Penggambaran model benda uji. 
Material dan section properties

Data material baja dimasukkan pada menu property dengan nilai berat jenis $7800 \mathrm{~kg} / \mathrm{m}^{3}$, modulus elastis $200.000 \mathrm{MPa}$ dan poison rasio 0,3 seperti pada Gambar 2 .
Load

Pada tahap ini pembebanan diaplikasikan dengan menggunakan fasilitas Load manager. Tipe pembebanan yang di aplikasikan pada pemodelan ini adalah pressure seperti pada Gambar 3 dan Gambar 4.

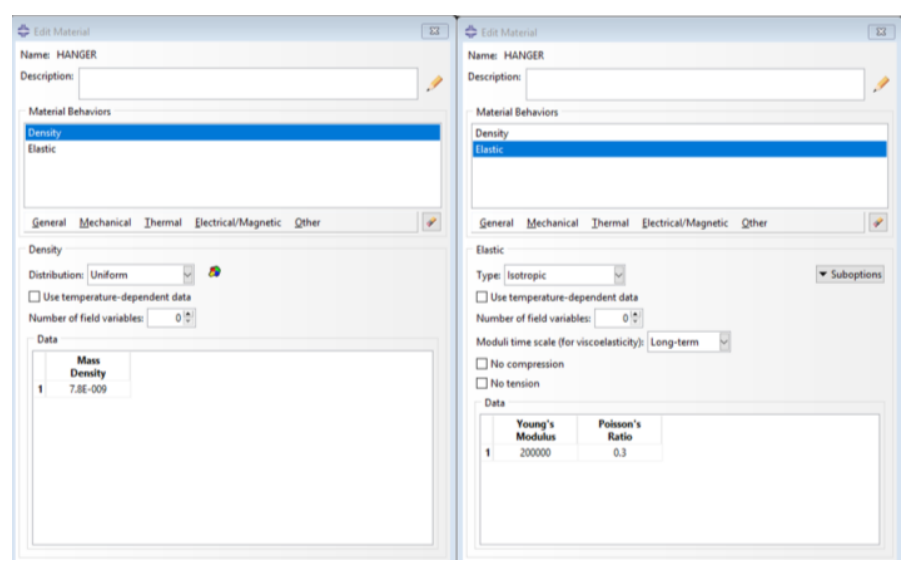

GAMBAR 2. Data material properties yang digunakan

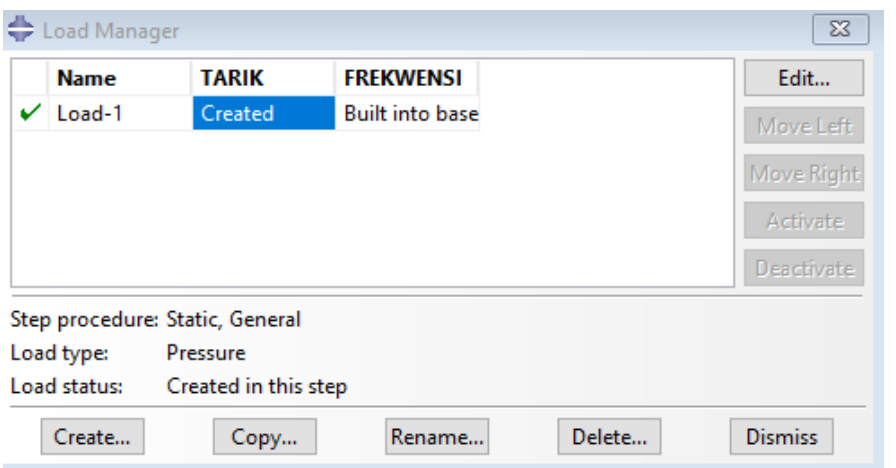

GAmbar 3. Pembebanan dengan tipe pressure

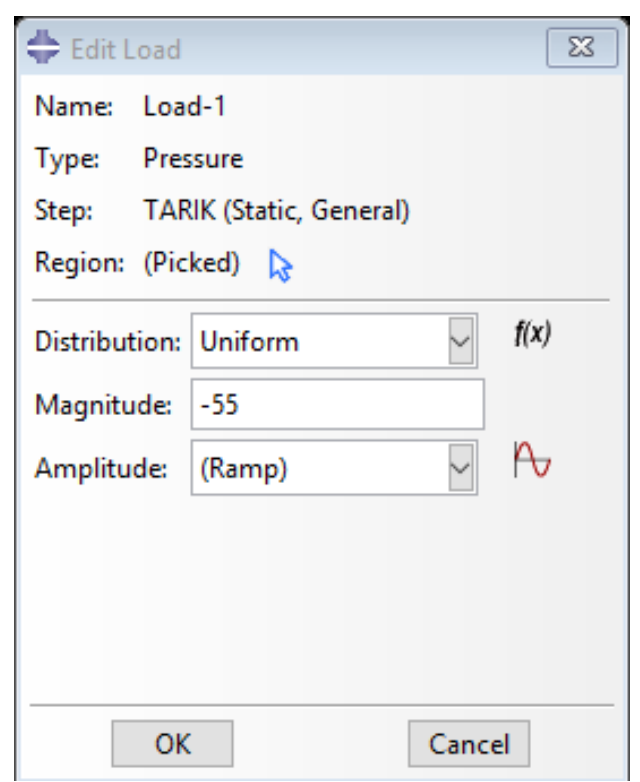

GAMBAR 4. Data gaya yang diaplikasikan dalam bentuk tegangan. 


\section{Boundary Condition}

Boundary condition digunakan untuk mengaplikasikan kondisi batas pada pemodelan. Kondisi batas yang di aplikasikan pada ujung elemen hanger berupa sendi-sendi dengan tipe displacement dan rotation seperti pada Gambar 5 dan Gambar 6.

\section{Step}

Step berfungsi untuk mengatur tahapan pada proses analisis. Pada proses pemodelan step terdiri dari beberapa tahapan. Step 1 initial condition yang berfungsi untuk mendifinisikan kondisi batas tumpuan. Step 2 static general digunakan untuk aplikasi gaya aksial. Step 3 frequency yang digunakan untuk menghitung frekuensi alami model seperti terlihat pada Gambar 7.

\section{Job Manager}

Pada job manager seluruh model yang sudah disiapkan akan di running dengan menekan tombol submit seperti pada Gambar 8.

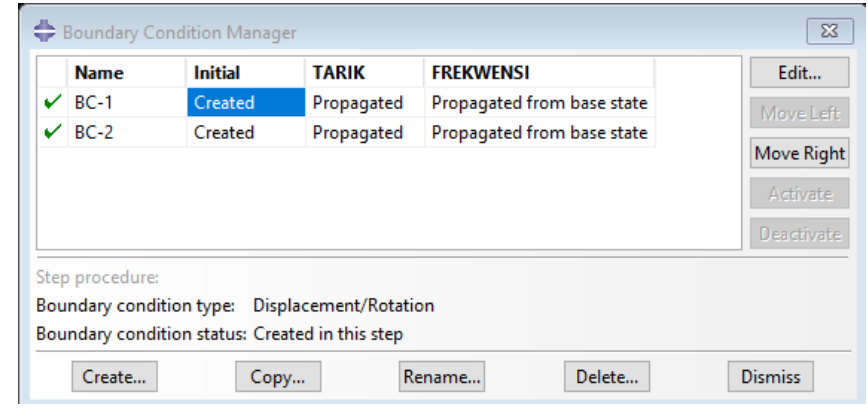

GAMBAR 5. Kondisi batas model

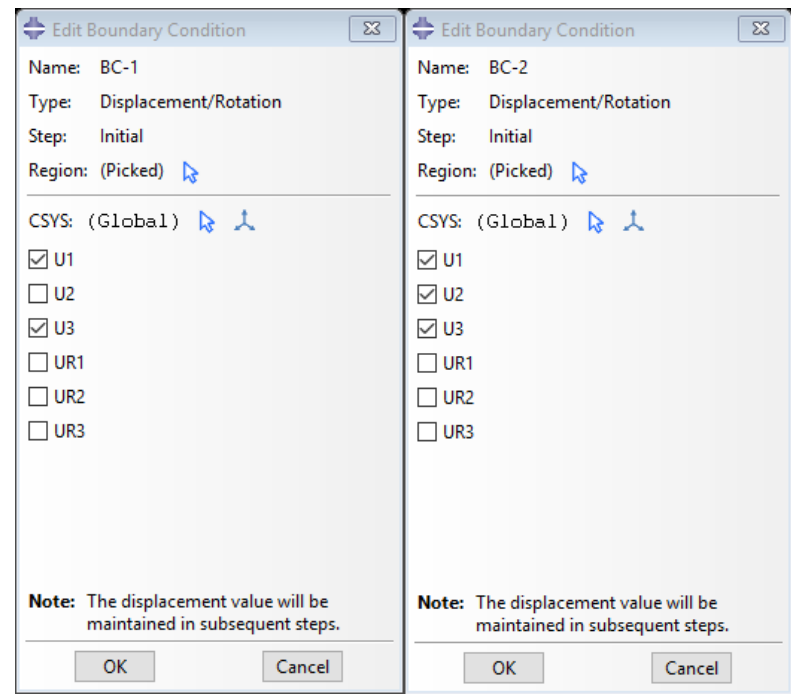

GAMBAR 6. Aplikasi kondisi batas model dengan tipe displacement/rotation

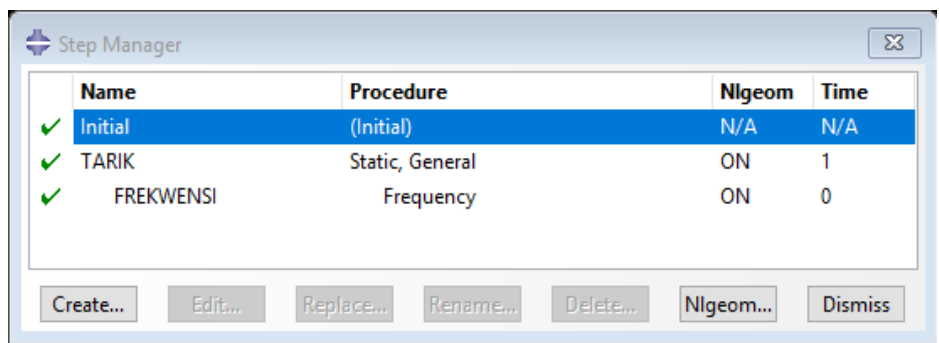

GAMBAR 7. Tahapan pemodelan benda uji 


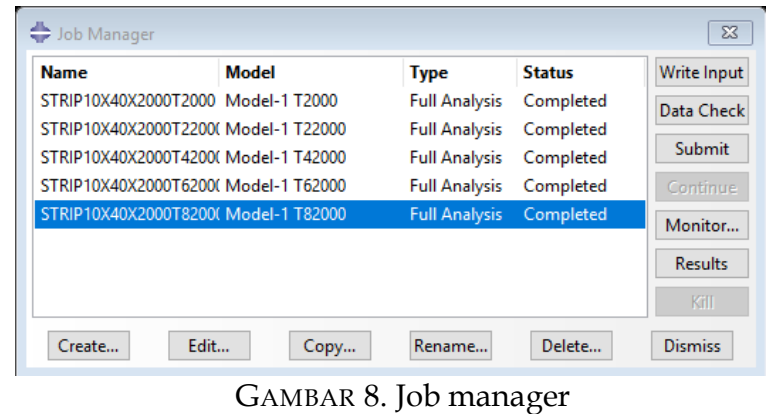

\section{Vizualisation}

Tahap Visualilisation digunakan untuk menampilkan keluaran analisis numerik secara grafis meliputi kontur tegangan, regangan, displacement, damage parameter, dan parameter output lainnya dari model yang sudah selesai di running seperti pada Gambar 9.

\section{Modal Frequencies}

Untuk mendapatkan nilai frekuensi alami pada benda uji yang dibebani gaya aksial tarik, tahapan pemodelan abaqus terdiri dari beberapa tahap.
Tahap 1: Pembebanan tarik aksial diaplikasikan pada salah satu ujung benda uji dengan menggunakan pemebebanan tipe pressure load. Beban tersebut akan berpengaruh tegangan internal pada model yang diikuti oleh peningkatan kekakuan. Pada tahap ini dilakukan analisis non linier geometri.

Tahap 2 : Setelah benda uji diberikan beban aksial tarik dan mengalami perpanjangan, analisis eigenvalue dengan menggunakan matrik masa dan matrik kekakuan untuk mendapatkan nilai frekuensi alami. Visualisasi mode shape hasil pemodelan dapat dilihat pada Gambar 10 sampai Gambar 13.

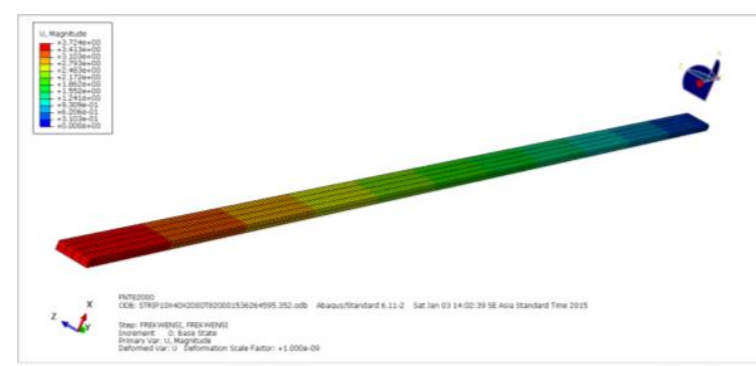

GAMBAR 9. Visualisasi hasil running model.

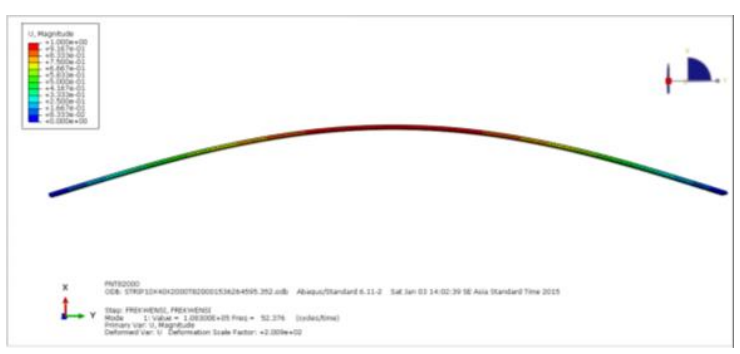

GAMBAR 10. Visualisasi bentuk mode pertama.

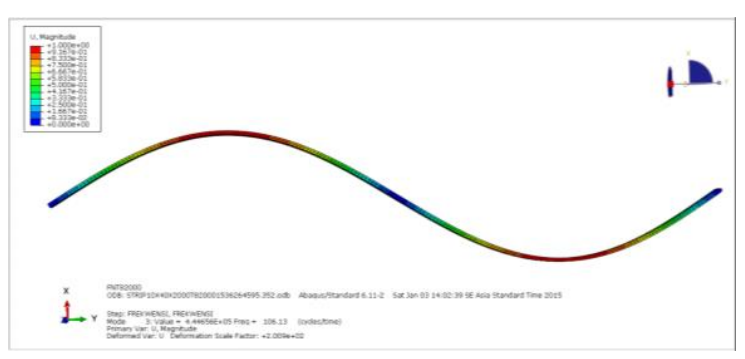

GAMBAR 11. Visualisasi bentuk mode kedua 


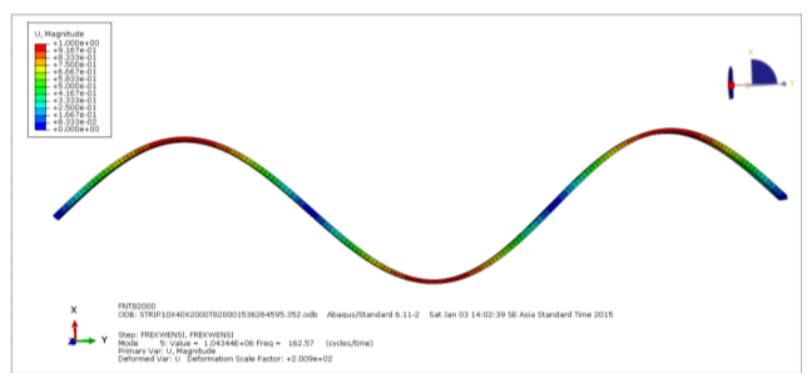

GAMBAR 12. Visualisasi bentuk mode ketiga

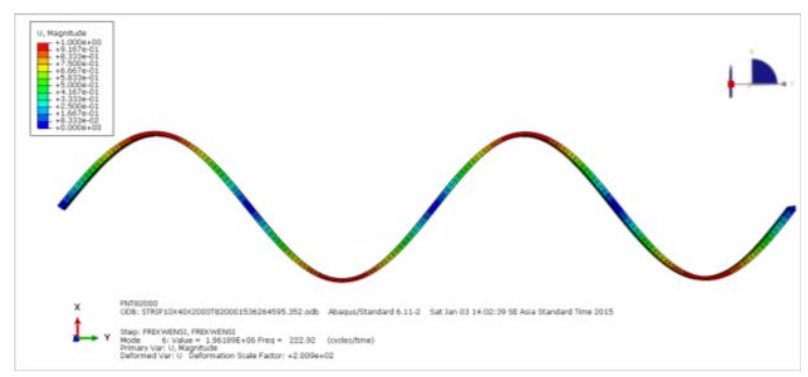

GAMBAR 13. Visualisasi bentuk mode keempat

\section{HASIL DAN PEMBAHASAN}

Perhitungan frekuensi alami dilakukan dengan menngunakan rumus analitik string, stokey dan beam-string yang dibandingkan dengan hasil pemodelan numerik menggunakan software Abaqus 6.11. Hubungan antara frekuensi alami dan beban tarik pada setiap tahap pembebanan dapat dilihat pada Gambar 14-16.

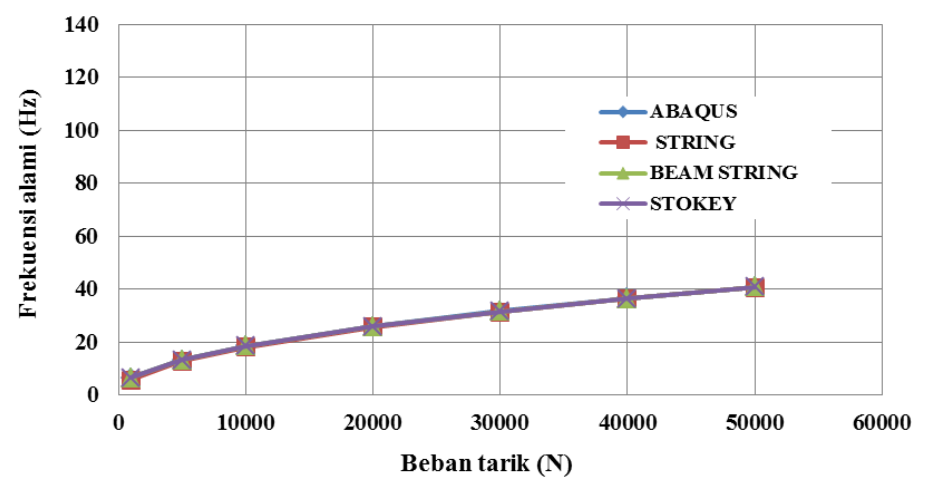

GAMBAR 14. Perbandingan frekuensi alami hasil perhitungan analitik dan pemodelan numerik pada mode pertama.

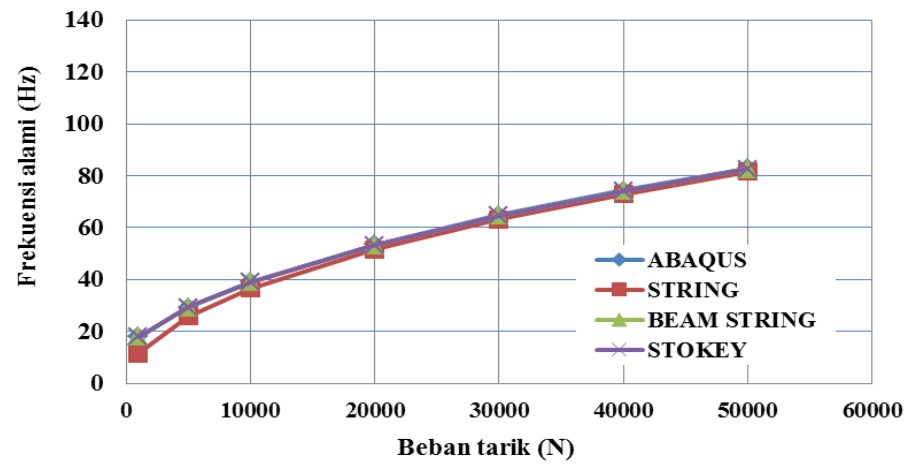

GAMBAR 15. Perbandingan frekuensi alami hasil perhitungan analitik dan pemodelan numerik pada mode kedua. 


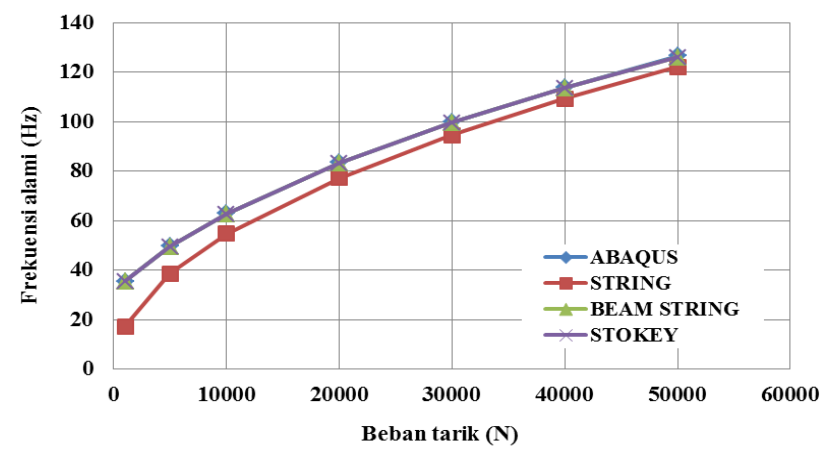

GAMBAR 16. Perbandingan frekuensi alami hasil perhitungan analitik dan pemodelan numerik pada mode ketiga.

Dari Gambar 14 - Gambar 16 dapat dilihat grafik hubungan antara beban tarik dan frekuensi alami pada mode pertama, kedua dan ketiga. Perbedaan nilai frekuensi alami hasil pemodelan numerik terhadap rumus analitik string, stokey, beam-string pada pembebanan $5.000 \mathrm{~N}$ dan pada mode pertama mempunyai nilai sebesar $3,75 \%, 0,42 \%$, dan $0,24 \%$. Perbedaan nilai frekuensi alami pada mode kedua mempunyai nilai sebesar $13,65 \%, 0,46 \%$ dan $0,27 \%$. Perbedaan nilai frekuensi alami pada mode ketiga mempunyai nilai sebesar $28,41 \%, 0,35 \%$ dan $0,27 \%$.

Perbedaan nilai frekuensi alami hasil pemodelan numerik terhadap rumus analitik string, stokey, beam-string pada pembebanan $50.000 \mathrm{~N}$ dan pada mode pertama mempunyai nilai sebesar $0,61 \%, 0,43 \%$, dan $0,25 \%$. Perbedaan nilai frekuensi alami pada mode kedua mempunyai nilai sebesar $1,65 \%, 0,42 \%$ dan $0,23 \%$. Perbedaan nilai frekuensi alami pada mode ketiga mempunyai nilai sebesar $3,6 \%, 0,51 \%$ dan $0,44 \%$. Rumus analitik beamstring dan stokey mempunyai kesesuaian dengan hasil pemodelan numerik pada mode pertama, kedua dan ketiga.

Rumus analitik string mempunyai nilai perbedaan terhadap frekuensi alami hasil pemodelan numerik mode pertama sebesar $3,75 \%$ pada beban $5.000 \mathrm{~N}$ dan $0,61 \%$ pada beban $50.000 \mathrm{~N}$. Pada mode kedua sebesar $13,65 \%$ pada beban $5000 \mathrm{~N}$ dan $1,65 \%$ pada beban $50.000 \mathrm{~N}$. Pada mode ketiga sebesar $28,41 \%$ pada beban $5000 \mathrm{~N}$ dan $3,6 \%$ pada beban $50.000 \mathrm{~N}$. Rumus analitik string mempunyai perbedaan lebih besar dibanding dengan hasil perhitungan beam-string dan stokey, hal tersebut dikarenakan rumus analitik string mengabaikan parameter momen inersia (I) dalam perhitungannya.
Perbedaan frekuensi alami benda uji dengan menggunakan rumus analitik (string, beamstring, stokey) dan hasil pemodelan numerik mempunyai nilai terkecil pada mode pertama yaitu sebesar $3,75 \%$ pada beban $5.000 \mathrm{~N}$ dan $0,61 \%$ pada beban $50.000 \mathrm{~N}$. Dengan demikian dapat disimpulkan bahwa frekuensi alami hasil pemodelan benda numerik sesuai dengan rumus analitik (string, stokey dan beam-string) pada mode yang pertama. Sehingga mode pertama direkomendasikan untuk digunakan dalam estimasi gaya dengan metode vibrasi.

\section{KESIMPULAN}

Frekuensi alami hasil pemodelan benda numerik sesuai dengan rumus analitik string, stokey dan beam-string pada mode yang pertama. Sehingga mode pertama direkomendasikan untuk digunakan dalam estimasi gaya dengan metode vibrasi.

\section{DAFTAR PUSTAKA}

Humar, J. L. (1990). Dynamics of structures, Prentice Hall, Upper SaddleRiver, NJ.

Irvine, H. M, (1981). Cable Structure, MIT Pers, Cambridge, M.A, USA.

Saxon dan Chan (1953) Mode of vibration of a suspended chain. Quarterly Journal of Mechanics and Applied Mathemathics, Vol.6, No.6, pp. 273285.

Shimada, T. (1994). Estimating method of cable tension from natural frequency of high mode. Proc. JSCE, 501(1-29), 163-171. 
Stokey.W.F,(1998), Vibration of Systems

having distributed mass and elasticity, 4th Edition, McGraw-Hill.

PENULIS:

\section{Guntur Nugroho}

Program Studi Teknik Sipil, Fakultas Teknik, Universitas Muhammadiyah Yogyakarta, Bantul, D.I. Yogyakarta.

Email: guntur.nugroho@umy.ac.id 